\title{
References
}

1 Drummond MB, Kirk GD. HIV-associated obstructive lung diseases: insights and implications for the clinician. Lancet Respir Med 2014; 2: 583-592.

2 Brown J, Lipman M. Community-acquired pneumonia in HIV-infected individuals. Curr Infect Dis Rep 2014; 16: 397.

3 Feikin DR, Feldman C, Schuchat A, et al. Global strategies to prevent bacterial pneumonia in adults with HIV disease. Lancet Infect Dis 2004; 4: 445-455.

4 Benito N, Moreno A, Miro JM, et al. Pulmonary infections in HIV-infected patients: an update in the 21st century. Eur Respir J 2012; 39: 730-745.

5 Kim JH, Psevdos G, Gonzalez E, et al. All-cause mortality in hospitalized HIV-infected patients at an acute tertiary care hospital with a comprehensive outpatient HIV care program in New York City in the era of highly active antiretroviral therapy (HAART). Infection 2013; 41: 545-551.

6 Jordano Q, Falcó V, Almirante B, et al. Invasive pneumococcal disease in patients infected with HIV: still a threat in the era of highly active antiretroviral therapy. Clin Infect Dis 2004; 38: 1623-1628.

7 Garcha DS, Thurston SJ, Patel AR, et al. Changes in prevalence and load of airway bacteria using quantitative PCR in stable and exacerbated COPD. Thorax 2012; 67: 1075-1080.

8 Gordon SB, Musaya J, Wilson L, et al. HIV infected adults do not have an excess of colonising bacteria in their large airways. BMC Infect Dis 2003; 3: 29.

9 Lipman MC, Ainscough S, Deery AR, et al. Infrequency of pulmonary microbial colonisation prior to respiratory disease in HIV-infected individuals. Eur J Clin Microbiol Infect Dis 2000; 19: 699-703.

10 Patel IS, Seemungal TA, Wilks M, et al. Relationship between bacterial colonisation and the frequency, character, and severity of COPD exacerbations. Thorax 2002; 57: 759-764.

11 Wilkinson TM, Patel IS, Wilks M, et al. Airway bacterial load and FEVı decline in patients with chronic obstructive pulmonary disease. Am J Respir Crit Care Med 2003; 167: 1090-1095.

12 Cabello H, Torres A, Celis R, et al. Bacterial colonization of distal airways in healthy subjects and chronic lung disease: a bronchoscopic study. Eur Respir J 1997; 10: 1137-1144.

13 Weinreich UM, Korsgaard J. Bacterial colonisation of lower airways in health and chronic lung disease. Clin Respir J 2008; $2: 116-122$.

14 Tumkaya M, Atis S, Ozge C, et al. Relationship between airway colonization, inflammation and exacerbation frequency in COPD. Respir Med 2007; 101: 729-737.

15 Siemieniuk RA, Gregson DB, Gill MJ. The persisting burden of invasive pneumococcal disease in HIV patients: an observational cohort study. BMC Infect Dis 2011; 11: 314.

16 Morris A, Beck JM, Schloss PD, et al. Comparison of the respiratory microbiome in healthy nonsmokers and smokers. Am J Respir Crit Care Med 2013; 187: 1067-1075.

17 Cui L, Lucht L, Tipton L, et al. Topographic diversity of the respiratory tract mycobiome and alteration in HIV and lung disease. Am J Respir Crit Care Med 2015; 191: 932-942.

\section{Nasal decongestant exposure in patients with pulmonary arterial hypertension: a pilot study}

To the Editor:

In the scientific and medical community, it is recognised that exposure to certain drugs could promote the development of pulmonary arterial hypertension (PAH). These drugs, with a "class effect" (amphetamine-like) or not (dasatinib), are prescribed for serious (dasatinib, interferons) or moderate (benfluorex) pathologies and do not induce PAH in all patients [1-9]. As a result, assessment of drug history exposure from PAH patients has become essential for providing optimal disease management [10].

Nasal decongestants are a class of drugs used by nasal or oral route for symptomatic treatment of nasal obstruction. Some of them have a chemical structure similar to amphetamine, as had been observed for fenfluramine derivatives [11]. According to the French national agency for medicines and health products safety, the mean annual sales of nasal decongestants between 2008 and 2011 in France were respectively (all specialties combined): 17.5 million boxes per year for systemic/oral and 19.3 million of units per year for nasal decongestants. Despite the fact that nasal decongestants are largely used, these drugs are not trivial and induce rare but serious cardiovascular or neurological side effects [12]. Phenylpropanolamine, also known as norephedrine, is a drug of the phenethylamine chemical class with a structure similar to amphetamine [13]. Phenylpropanolamine was used as a stimulant, nasal decongestant, and also as an anorectic agent. The study of pulmonary hypertension in America (SOPHIA) carried out between 1998 
and 2001, found that over-the-counter appetite suppressants pills containing phenylpropanolamine were a risk factor for developing PAH [14]. In addition, an overdose-related fatal case of PAH in a child treated for a cold with a high dose of phenylpropanolamine was reported in 2004 [15]. Due to the rare but serious side effects, phenylpropanolamine was withdrawn from the US market in 2000. In Europe, phenylpropanolamine was withdrawn in France in 2001 but was still marketed in several countries such as Belgium or Switzerland. Despite this fact, other molecules similar to phenylpropanolamine such as ephedrine or pseudoephedrine are still commercialised in several medications. The majority of these therapies are easily available (over-the-counter) and are often used for self-medication. To date, no specific research on the impact of nasal decongestants exposure on the development of PAH has been performed, probably in part due to trivialisation of these treatments. However, given the reported adverse events associated with these drugs and their vasoconstrictor property, assessment of nasal decongestants exposure in PAH patients was needed.

Our study was conducted from December 15, 2012 to July 30, 2013, in the French pulmonary hypertension referral centre, with ethics committee approval (Comité d'Evaluation des Protocoles de Recherche Observationnelle de la Société Française de Pneumologie; ref: CEPRO 2013-009). We retrospectively collected nasal decongestant exposure data from patients before their PAH diagnosis and compared them with nasal decongestant exposure in a control group. The study cohorts consisted of a group of patients suffering from idiopathic, heritable or drug-induced $\mathrm{PAH}$ and a control group consisting of people accompanying the included patients (family member or home help person). The control group was used as the reference to determine the normal frequency of nasal decongestant exposure in the population from which the PAH cases were derived. In order to collect data on drug-exposure in PAH patients and their accompaniers, a systematic validated questionnaire was performed by a pharmacist specialised in PAH. In order to cross-check drug exposure information obtained from the interview, and/or collect potential additional data, the general practitioner and the pharmacist of each subject were also contacted. During the patient's interview, nasal decongestant exposure before PAH diagnosis as well as other suspected drugs potentially promoting PAH were assessed. As the assessment was about the period before the PAH diagnosis, none of patients received any specific treatment for PAH, which could promote nasal congestion. For the control population, nasal decongestant exposure was assessed until the date of the interview.

As the collected information about vasoconstrictor nasal decongestant exposure was semi-qualitative (" 2 times a year", "3 or 4 times"), an accurate estimation of exposure duration was unrealisable. Therefore, for each subject, nasal decongestant exposure was translated as an estimated number of treatment periods (C), using a specific scale performed for the study. This tool has allowed a classification of each subject according to consumption categories respecting the principle of never overestimating an exposure.

A total of 99 exposure assessments were obtained in PAH patients and 58 in the control group. 68 women and 31 men were interviewed in the PAH group, whereas 29 women and 29 men in the control group. The median ages were 56.2 years in PAH patients and 52.3 years in controls $(\mathrm{p}>0.05)$. The median (range) time from PAH diagnosis to study interview was 3.8 years $(0-22)$. At least one health professional (the general practitioner and/ or the pharmacist) of each subject was successfully contacted (additional data obtained) for $64.6 \%$ of patients and $96.6 \%$ of controls. A history of nasal decongestants exposure $(C \geqslant 1)$ was found in $70.7 \%$ of PAH patients and $79.3 \%$ of controls $(\mathrm{p}>0.05)$. In PAH patients previously exposed to nasal decongestants, $29.3 \%$ presented another PAH drug exposure risk factor, such as a previous use of amphetamine, appetite suppressant, cocaine, dasatinib and/or interferon. In PAH patients with exposure to nasal decongestant of $\mathrm{C} \geqslant 2$ courses, the characteristics of the population are different with a lower median age at diagnosis and an increased female:male sex ratio. This trend is confirmed in PAH patients with an exposure to nasal decongestant of $\mathrm{C}>10$ courses (table 1). However, these observations should be interpreted with caution. Foremost, the analysis does not seem to show any other drug or toxic risk factors more commonly associated. In addition, differences in the age of diagnosis and sex ratio might to be explained by different consumption behaviours between generations, by different memory capacities or by sampling fluctuations. Similarly, the lower age of diagnosis could also be explained by the scientific advances, particularly in genetic research of PAH. Among subjects with an exposure to nasal decongestants of $\mathrm{C} \geqslant 2$ courses, the most reported agent was oral pseudoephedrine which exists in more than 10 different decongestive therapies. The other drugs often reported were nasal naphazolin, nasal oxymetazolin, nasal tuaminoheptan and oral phenylpropanolamine.

Our study showed there was no significant difference of nasal decongestants exposure between PAH patients and their accompanying persons. This specific research of nasal decongestants exposure allowed us to highlight the high level of exposure in PAH patients and accompaniers confirming the large consumption of these drugs in the general population in France. While no significant difference has been reported, further studies will be required with larger numbers of patients to answer this question fully. PAH has a complex pathophysiology and it is possible that nasal decongestants could be one of several risk factors for $\mathrm{PAH}$, which when combined lead to the development of the disease. For example it has been suggested that patients with mutations in BMPR2 
TABLE 1 Characteristics of study populations

\begin{tabular}{|c|c|c|c|c|c|c|c|c|c|}
\hline $\mathrm{C}$ by group & Effective & $\begin{array}{c}\text { Sex ratio } \\
\text { female/male }\end{array}$ & Age years & $\begin{array}{l}\text { Age at time of } \\
\text { diagnosis years }\end{array}$ & \multicolumn{5}{|c|}{ PAH form } \\
\hline \multicolumn{10}{|l|}{ PAH } \\
\hline Total & 99 & 2.2 & $56.2(20.2-84.6)$ & $50.6(16.3-81.9)$ & 50 (50.5) & 15 (15.2) & $16(16.2)$ & $5(5.0)$ & $13(13.1)$ \\
\hline$C=2-10$ & $39(39.4)$ & 2.9 & $53.4(20.9-75.3)$ & $41.1(19.9-73.9)$ & $18(46.2)$ & $6(17.9)$ & $8(20.5)$ & $3(3.7)$ & $4(7.7)$ \\
\hline$C>10$ & 23 (23.2) & 4.8 & $42.1(21.7-71.0)$ & $38.2(21.6-69.4)$ & 15 (65.2) & $2(8.7)$ & $3(13.1)$ & $2(8.7)$ & $1(4.3)$ \\
\hline \multicolumn{10}{|l|}{ Controls } \\
\hline Total & 58 & 1 & $52.3(27.3-82.8)$ & & & & & & \\
\hline $\mathrm{C}=0$ & 12 (20.7) & 1 & $65.3(31.4-82.8)$ & & & & & & \\
\hline$C=1$ & $6(10.3)$ & 5 & $53.9(30.6-73.5)$ & & & & & & \\
\hline
\end{tabular}

Data are presented as n, $\mathrm{n}(\%)$ or median (range). BMPR2: bone morphogenetic protein receptor type II; PVOD: pulmonary veno-occlusive disease.

(bone morphogenetic protein receptor type II) develop PAH after a shorter exposure to fenfluramine than people without the mutation [16]. In our study, the low number of patients with BMPR2 mutation does not allow an analysis of this hypothesis. Our study has other limitations. Firstly, there was a low number of control subjects included. This observation is due to the choice of a methodology based on matched control group to avoid an environment bias. Unfortunately some control candidates were unavailable or refused to participate. Secondly, the assessment of nasal decongestant exposure was limited by recall bias where some patients were interviewed many years after the diagnosis of PAH. Moreover, nasal decongestants are very common and are found in various drugs. The use of supplemental information from the general practitioners and pharmacists reduces this bias. Finally, there was a lack of specific research on cardiopulmonary diseases and specific treatments potentially leading to nasal congestion in the control group. These limitations had been taken into account. Thus, the extension study was now limited to patients with a PAH diagnosed within 2 years to avoid recall bias, and control group is asked about diseases and treatments exposure.

In conclusion, this study allowed the implementation of a data collection methodology in our centre. Assessment of drug exposure prior PAH diagnosis could highlight precious information for the future in terms of signal detection (other suspected drugs or specific characteristics of patients associated with specific drug exposure in) as well as strengthening the drug monitoring system in the French pulmonary hypertension referral centre.

@ERSpublications

More studies are needed to measure nasal decongestant exposure in patients with pulmonary arterial hypertension http://ow.ly/OFxs8

Swanny Perrin ${ }^{1,2}$, David Montani ${ }^{2,3,4}$, Caroline O'Connell ${ }^{2,4}$, Sven Günther ${ }^{2,3,4}$, Barbara Girerd ${ }^{2,3,4}$, Laurent Savale $^{2,3,4}$, Christophe Guignabert ${ }^{3,4}$, Olivier Sitbon ${ }^{2,3,4}$, Gerald Simonneau ${ }^{2,3,4}$, Marc Humbert ${ }^{2,3,4}$ and $^{2}$ Marie-Camille Chaumais ${ }^{1,3,5}$

${ }^{1}$ Université Paris-Sud, Faculté de Pharmacie, Châtenay Malabry, France. ${ }^{2}$ AP-HP, Centre National de Référence de l'Hypertension Pulmonaire Sévère, Département Hospitalo-Universitaire (DHU) Thorax Innovation, Service de Pneumologie et Réanimation Respiratoire, Hôpital Bicêtre, Le Kremlin-Bicêtre, France. ${ }^{3}$ UMRS 999, INSERM et Univ. Paris-Sud, Laboratoire d'Excellence (LabEx) en Recherche sur le Médicament et l'Innovation Thérapeutique (LERMIT), Centre Chirurgical Marie Lannelongue, Le Plessis Robinson, France. ${ }^{4}$ Université Paris-Sud, Faculté de Médecine, Le Kremlin-Bicêtre, France. ${ }^{5}$ AP-HP, Service de Pharmacie, Département Hospitalo-Universitaire (DHU) Thorax Innovation, Hôpital Antoine Béclère, Clamart, France.

Correspondence: Marie-Camille Chaumais, Hôpital Antoine Béclère, Service de Pharmacie, 157 rue de la porte de Trivaux, 92140 Clamart, France. E-mail: marie-camille.chaumais@u-psud.fr

Received: Jan 132015 | Accepted after revision: June 22015 | First published online: July 232015

Support statement: This study was supported by the Agence Nationale de Sécurité du Médicament et des produits de santé (ANSM) and the French patient association HTAPFrance.

Conflict of interest: Disclosures for this manuscript can be found alongside the online version of this article at erj.ersjournals.com 
Acknowledgements: We acknowledge the French pulmonary hypertension pharmacovigilance network, VIGIAPATH, supported by the French national agency for medicines and health products safety (Agence Nationale de Sécurité du Médicament et des produits de santé (ANSM)) as well as the French patient association HTAPFrance.

\section{References}

1 Simonneau G, Gatzoulis MA, Adatia I, et al. Updated clinical classification of pulmonary hypertension. J Am Coll Cardiol 2013; 62: D34-D41.

Gurtner HP. Aminorex and pulmonary hypertension. A review. Cor Vasa 1985; 27: 160-171.

Kay JM, Smith P, Heath D. Aminorex and the pulmonary circulation. Thorax 1971; 26: 262-270.

Simonneau G, Fartoukh M, Sitbon O, et al. Primary pulmonary hypertension associated with the use of fenfluramine derivatives. Chest 1998; 114: 195S-199S.

5 Savale L, Chaumais MC, Cottin V, et al. Pulmonary hypertension associated with benfluorex exposure. Eur Respir J 2012; 40: 1164-1172.

6 Chin KM, Channick RN, Rubin LJ. Is methamphetamine use associated with idiopathic pulmonary arterial hypertension? Chest 2006; 130: 1657-1663.

7 Montani D, Bergot E, Günther S, et al. Pulmonary arterial hypertension in patients treated by dasatinib. Circulation 2012; 125: 2128-2137.

8 Groeneveldt JA, Gans SJM, Bogaard HJ, et al. Dasatinib-induced pulmonary arterial hypertension unresponsive to PDE-5 inhibition. Eur Respir J 2013; 42: 869-870.

9 Savale L, Sattler C, Günther S, et al. Pulmonary arterial hypertension in patients treated with interferon. Eur Respir J 2014; 44: 1627-1634.

10 Montani D, Seferian A, Savale L, et al. Drug-induced pulmonary arterial hypertension: a recent outbreak. Eur Respir Rev 2013; 22: 244-250.

11 Broadley KJ. The vascular effects of trace amines and amphetamines. Pharmacol Ther 2010; 125: 363-375.

12 Commission nationale de pharmacovigilance-Compte rendu de la réunion du mardi 25 mars 2008. http://ansm. sante.fr/var/ansm_site/storage/original/application/bd7be64de27e31df5c8182983443353f.pdf Date last accessed: May 12, 2015.

13 Seferian A, Chaumais MC, Savale L, et al. Drugs induced pulmonary arterial hypertension. Presse Méd 2013; 42 : e303-310.

14 Walker AM, Langleben D, Korelitz JJ, et al. Temporal trends and drug exposures in pulmonary hypertension: an American experience. Am Heart J 2006; 152: 521-526.

15 Barst RJ, Abenhaim L. Fatal pulmonary arterial hypertension associated with phenylpropanolamine exposure. Heart 2004; 90: e42.

16 Souza R, Humbert M, Sztrymf B, et al. Pulmonary arterial hypertension associated with fenfluramine exposure: report of 109 cases. Eur Respir J 2008; 31: 343-348.

\section{Pulmonary tumour thrombotic microangiopathy: unclassifiable pulmonary hypertension?}

\section{To the Editor:}

Pulmonary hypertension $(\mathrm{PH})$ is defined as a mean pulmonary artery pressure $\geqslant 25 \mathrm{mmHg}$, and can be associated with multiple conditions. The diagnostic strategy and treatment of $\mathrm{PH}$ is heavily reliant on accurately classifying patients [1]. We recently identified two patients presenting with rapidly fatal $\mathrm{PH}$ of unknown aetiology, who were subsequently diagnosed at post mortem with pulmonary tumour thrombotic microangiopathy (PTTM). This is a rare, albeit likely under-diagnosed cause of PH, characterised by a remodelling pulmonary vasculopathy rather than simple tumoural obstruction. At present, it is unclear where PTTM fits within the current classification system.

Case 1 was a 58-year-old male smoker who presented with a short history of progressive breathlessness. Initial imaging at his local hospital was suggestive of an interstitial lung process with associated $\mathrm{PH}$, and he was transferred to our hospital for further assessment. Computerised tomography (CT)-pulmonary angiography (PA) excluded pulmonary embolism, and high-resolution cuts revealed widespread ground glass changes and interlobular septal thickening, consistent with interstitial and airspace oedema, rather than an interstitial lung process (figure 1a). Echocardiography revealed a moderately hypertrophic right ventricle with reduced longitudinal systolic function and an estimated right ventricular systolic pressure (RVSP) of $68 \mathrm{mmHg}$. The left ventricle was hypertrophic with good systolic function. Subsequent right and left heart catheterisation confirmed increased pulmonary vascular resistance (5.2 Wood units), with a 